\title{
Menyoal Konsep Kesembuhan Tubuh: Suatu Kajian Teologis
}

\author{
Questioning the Concept of Body Healing: A Theological Study
}

\section{Author: \\ - Kalis Stevanus \\ Affiliation: \\ ${ }^{1}$ Sekolah Tinggi Teologi Tawangmangu kalisstevanus91@gmail.com \\ Dates: \\ Submitted: \\ 25 August 2021 \\ Accepted: \\ 20 October 2021 \\ Published: \\ 12 November 2021 \\ DOI: \\ 10.46494/psc.v17i2.154}

\section{Copyright:}

(C) 2021. The Authors. Licensee: This work is licensed under the Creative Commons Attribution-ShareAlike 4.0 International License.

\begin{abstract}
The Bible records many texts dealing with the subject of healing the body. This study uses a literature approach by digging sources from journal articles and books and then analyzing them using the Bible to produce in-depth and comprehensive theological conclusions. The conclusion of this study shows that healing of the body can occur through natural healing, medical healing, and divine healing miracles or miracles. The implication is theological; Christians may believe that miracle healing still exists and can pray to God so that healing that comes from Him can be experienced now. And the practical implication is that Christians must still be responsible for taking care of their bodies' health proportionally because their bodies are the temple of God.

[Alkitab mencatat banyak teks yang berhubungan dengan topik kesembuhan tubuh. Penelitian ini menggunakan pendekatan pustaka dengan menggali sumber dari artikel jurnal dan buku-buku kemudian menganalisisnya dengan menggunakan Alkitab untuk menghasilkan kesimpulan teologis yang mendalam dan komprehensif. Kesimpulan penelitian ini menunjukkan bahwa kesembuhan tubuh dapat terjadi melalui kesembuhan alamiah, kesembuhan medis dan mujizat kesembuhan ilahi atau mujizat. Implikasinya secara teologis, orang Kristen boleh yakin dan memercayai bahwa mujizat kesembuhan masih ada dan bisa berdoa kepada Allah supaya kesembuhan yang berasal daripada-Nya dapat dialaminya sekarang. Dan implikasi praktisnya, orang Kristen tetap harus bertanggung jawab untuk merawat kesehatan tubuhnya secara proporsional sebab tubuhnya adalah bait Allah.]
\end{abstract}

Research Contribution: Hasil penelitian ini menyumbangkan teologi kesembuhan di dalam ilmu praktika dan kesembuhan ilahi.

Keywords: healing, God's power, theology, miracle, body

\section{Pendahuluan}

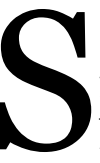
alah satu topik atau isu teologis dalam Kekristenan yang hingga hari ini masih hangat diperbincangkan bahkan menjadi perdebatan di kalangan kaum awam (jemaat) hingga teolog adalah perihal kesembuhan tubuh. Ada berbagai ragam pendapat tentang kesembuhan tubuh. Ada yang mengatakan kesembuhan tubuh melalui kesembuhan ilahi masih berlangsung hingga hari ini. Terutama kelompok Pentakostal dan Karismatik begitu antusias menekankan dan mempromosikan kuasa mujizat di dalam ibadah-ibadah mereka. 
Salah satu penelitian yang dilakukan Minggus Minarto Pranoto tentang doktrin mujizat kesembuhan dari perspektif teologi Pentakostal. Ia memberikan contoh adalah Gereja Isa Almasih yang berasal dari tradisi gereja yang beraliran Pentakostal. Dikatakan Pranoto perihal doktrin mujizat kesembuhan ini tertuang di Tata Gereja GIA tahun 2008. Dengan kata lain, GIA tetap meyakini dan mengajarkan praktik mujizat kesembuhan. ${ }^{1}$ Slogan mereka adalah "mujizat masih ada". Ayat Alkitab yang menjadi favorit dikutip dan dikhotbahkan adalah "Dialah yang memikul kelemahan kita dan menanggung penyakit kita" (Mat.8:17). Ketika Tuhan Yesus berada di rumah Petrus dan menyembuhkan sakit demamnya ibu mertua Petrus. Tapi tidak hanya berhenti di situ. Pada malam itu juga dibawalah kepada Tuhan Yesus banyak orang yang kerasukan setan dan Ia mengusir roh-roh itu serta menyembuhkan orang-orang yang menderita sakit. Biasanya juga dalam praktik doa penyembuhan, para tokoh Pentakostal maupun Karismatik menyebut "bilur-bilur Yesus menyembuhkan". Seperti diungkapkan Sukono, Alkitab adalah Firman Allah yang tak mungkin keliru, namun seringkali orang Kristen mengutip ayat secara keliru atau tidak akurat sebagai rujukan untuk menyampaian pesan tertentu. ${ }^{2}$

Bagi pihak yang tidak sependapat (baca Ir.Herlianto) dengan gerakan PentakostalKarismatik, mengkritik atau menyudutkan mengenai pengalaman-pengalaman supranatural yang dipraktikkan kaum Pentakostal-Karismatik cenderung mirip dengan apa yang dipraktikkan dalam dunia

\footnotetext{
${ }^{1}$ Minggus Minarto Pranoto, "Kesembuhan, Penebusan, Dan Kebaikan Allah Dalam Teologi Pentakostal," Jurnal Abdiel: Khazanah Pemikiran Teologi, Pendidikan Agama Kristen dan Musik Gereja 1, no. 1 (2017): 8198.

${ }_{2}^{2}$ Djoko Sukono, "Alkitab: Penyataan Allah Yang Diilhamkan," PASCA: Jurnal Teologi dan Pendidikan Agama Kristen 15, no. 1 (November 30, 2019): 28-34, https://journal.stbi.ac.id/index.php/PSC/article/view/ 66.
}

perdukunan (sinkretis), sangat mistis dan tidak masuk akal. Pendapat tersebut dibantah oleh Djaka Silalahi di dalam bukunya Karismatik Bercampur dengan Perdukunan hendak menunjukkan kesalahpahaman Ir. Herlianto dalam menilai atau mencap semua Karismatik telah melakukan sinkretis dengan perdukunan (baca tidak alkitabiah). Ditegaskan Silalahi, bahwa kita tidak boleh membuat generalisasi semua Karismatik sinkretis. 3

Kelompok Pentakotalisme ini sangat menekankan kesembuhan ilahi karena mereka menganggap mujizat atau kesembuhan ilahi merupakan telah diberikan kepada percaya sebagai hak (privileges) karena telah ditebus Kristus. 4 Hak tersebut bisa diklaim asal percaya pada kuasa bilur-bilur Yesus. 5 Terkadang, penulis jumpai ada yang akhirnya menjadi ekstrim bilamana sakit tidak berobat ke dokter karena dianggap tidak beriman dan melecehkan bilur-bilur Yesus. Di pihak lain, ada juga kelompok Kristen yang fobia dengan praktik kesembuhan ilahi. Kesembuhan ilahi dianggap praktik hipnotis yang berfokus pada metode psikologi positive thinking atau sugesti pikiran. ${ }^{6}$ Bahkan ada juga anggapan praktik kesembuhan ilahi itu bukan tidak mungkin merupakan sebagai perbuatan nabi-nabi palsu yang disusupi oleh kuasa gelap (roh-roh jahat) sebagaimana pernah diperingatkan Tuhan Yesus di dalam Matius 24:23-24.

Realita yang demikian telah menimbulkan persoalan teologis di dalam Kekristenan. Menyoal kesembuhan tubuh melalui mujizat kesembuhan Ilahi, Siburian memberi komentar, bahwa fenomena kesembuhan ini (divine

3 Djaka Christianto Silalahi, Karismatik Bercampur Dengan Perdukunan? (Yogjakarta: Andi Offset, 2001).56

4 Sonny E. Zaluchu, "The Impact of Mediatisation in the Healing Ministry of African Preachers," Verbum et Ecclesia 42, no. 1 (April 20, 2021),

http://www.ve.org.za/index.php/VE/article/view/2198. 5 Kalis Stevanus, Penyesatan Terselubung Dalam Gereja Masa Kini (Yogjakarta: Randa's Family, 2017).56

${ }^{6}$ Kalis Stevanus, Ada Penyesat Yang Memplesetkan Injil Dalam Jemaat, Apa Sikap Anda (Yogjakarta: Pustaka Nusatama, 2016).157 
healing), memang sangat diminati orang Kristen, tapi sekaligus disalahmengerti oleh orang Kristen. Siburian menyebutkan ada gerakan faith healing yang mengkampayekan secara masif oleh kaum Karismatik dan dampaknya masih terasa sampai sekarang. Itu sebabnya pentingnya mengangkat atau mengisukan kembali topik dan dikaji ulang secara kritis agar dapat menghindari kesalahan teologisnya. Dan kemudian berefleksi injili mengenai prinsip kesembuhan ilahi yang lebih komprehensif. 7

Ajaran yang berkembang dewasa sekarang ini tentang kesembuhan tubuh perlu disikapi dengan bijak, yaitu tidak membiarkan pemikiran tersebut berkembang tanpa penjelasan dan pengertian yang benar, sehingga tidak menyesatkan umat Kristen. Penulis tidak mau berpihak pada salah satu pandangan di atas, tetapi mencoba menjawab persoalan tersebut secara lebih kritis dan alkitabiah terhadap berbagai pandangan tersebut.

Untuk menjawab pertanyaan-pertanyaan ini, dibutuhkan kajian teologis yang kuat secara biblikal tentang kesembuhan tubuh. Hasil pemikiran teologis ini diharapkan dapat menjawab kebingungan umat Kristen masa kini agar memiliki pemahaman yang utuh dan benar soal kesembuhan tubuh.

\section{Metode}

Kajian pembahasan ini menggunakan pendekatan kualitatif deskriptif untuk mendeskripsikan suatu fenomena yang dihadapi umat Kristen tentang kesembuhan tubuh. ${ }^{8}$ Untuk memecahkan persoalan tersebut, penulis menggunakan kajian pustaka

\footnotetext{
7 Togardo Siburian, "Tinjauan Ulang Terhadap

'Kesembuhan Ilahi”,"” STULOS Vol.17, no. no.1 (2019): 28-53.

8 Sonny Eli Zaluchu, "Strategi Penelitian Kualitatif Dan Kuantitatif Di Dalam Penelitian Agama," Evangelikal: Jurnal Teologi Injili dan Pembinaan Warga Jemaat 4, no. 1 (January 31, 2020): 28-38,
}

dengan menggali informasi dari litetarur yang relevan dengan objek penelitian. Data-data tersebut dianalisis dengan mencermati beberapa teks Alkitab yang berkenaan dengan kesembuhan tubuh untuk memeroleh kesimpulan yang komprehensif. Selanjutnya penulis memberikan implikasinya baik secara teologis dan praktis berdasarkan hasil analisis biblikal tersebut.

\section{Pembahasan}

Di dalam pembahasan ini, penulis akan menguraikan beberapa pokok penting yang perlu dipahami bertalian dengan kesembuhan tubuh, adalah sebagai berikut:

\section{Kesehatan Tubuh adalah Kehendak Tuhan sendiri}

Pada mulanya manusia diciptakan Allah dengan kondisi yang sempurna, ternasuk keadaan fisiknya, tanpa ada benih-benih sakit penyakit. Manusia benar-benar hidup dengan tubuh yang sehat dan prima. Karakter Allah yang kudus itu tidak memungkinkan sakit penyakit berasal dari pada-Nya (1 Yoh 1:5; 3:5). Adam dan Hawa diciptakan tanpa dosa dan tanpa benih penyakit. Manusia diciptakan serupa dan segambar dengan diri-Nya dalam kondisi yang ideal dan baik (Kej 1:31).9 Cherry mengemukakan pendapatnya bahwa pada awal mula penciptaan manusia, eksistensi mereka benar-benar sempurna, tidak terdapat penyakit dan penderitaan badani. Faktor inilah yang membawa eksistensi manusia pada kondisi kesehatan ideal dan sempurna.10 Dengan demikian, jelas dapat disimpulkan bahwa tubuh yang sehat adalah kehendak Tuhan sendiri.

https://journal.sttsimpson.ac.id/index.php/EJTI/article /view/167.

9 Kalis Stevanus, Penyesatan Terselubung Dalam Gereja Masa Kini (Yogyakarta: Randa’s Family, 2007),72.

10 Regina Cherry, Pengobatan Injil (Batam: Gospel Press, 2003),30. 


\section{Sakit Tubuh adalah Akibat Manusia Berdosa}

Telah disinggung di atas, sebab Tuhan itu mahasuci, mahabaik dan sempurna, sehingga penyakit tidak disebabkan oleh-Nya. Pada awal penciptaan manusia, mereka benar-benar dalam kondisi ideal, dan tanpa sakit penyakit apa pun. Sakit tubuh (penyakit) tidak berawal sebagai keadaan yang diciptakan, melainkan sebagai akibat penyalahgunaan kehendak bebas manusia sendiri yaitu makan buah yang dilarang oleh Tuhan. Manusia menjadi berdosa dan salah satu akibatnya adalah manusia mengalami sakit pada tubuhnya. Tubuhnya tidak lagi ideal tapi rentan terhadap berbagai penyakit. (Kej 3:17-19). Sejak tragedi kejatuhan tersebut, manusia mengalami kemerosotan fisik dan juga umurnya semakin pendek. Dosalah yang menjadi akar pangkal dari segala penderitaan manusia. Hingga kini, tidak ada seorang pun yang bebas dari sakit. ${ }^{11}$

Jadi, jelas bahwa asal muasal sakit tubuh adalah akibat manusia berdosa di hadapan Tuhan. Ketidaktaatan manusia pada perintah Tuhan tersebut menimbulkan konsekuensi fisik seperti kesakitan badani, sakit melahirkan dan mencari penghidupan di bumi serta pada akhirnya menghadapi kematian fisik (Ibr 9:27). Namun, mengatakan hal ini bukan berarti setiap sakit penyakit yang menyerang manusia pasti berasal dari akibat manusia berbuat dosa (faktor dosa) atau keadaan yang tidak berkenan pada Tuhan. Nyata sekali bahwa dosa bukanlah absolut penyebab satu-satunya dari sakit tubuh. Ternyata ada faktor lain, yang di luar ulah manusia sendiri, tapi karena seijin Tuhan sebagaimana dialami Ayub. Padahal sebenarnya, penderitaan badani Ayub disebabkan karena ulah si jahat seijin Tuhan.

Ayub dituduh oleh teman-temannya bahwa penderitaannya termasuk sakit tubuh yang

\footnotetext{
${ }^{11}$ Kalis Stevanus; Stefanus Marbun, "Memaknai Kisah Ayub Sebagai Refleksi Iman Dalam Menghadapi Penderitaan," LOGIA: Jurnal Teologi Pentakosta 1, no. 1 (2019): 23-40.
}

dialaminya itu dikarenakan karena ulah Ayub berdosa di hadapan Tuhan. Pemikiran ini biasanya disebut dengan retribusi atau teodisi, yaitu suatu konsep berpikir bahwa ketaatan mendatangkan kebahagian dan berkat, sedangkan ketidaktaatan atau hidup fasik menuai bencana dan penderitaan. Dengan kata lain, dalam dalam konsep teodisi sakit penyakit berasal dari hukuman Tuhan, sedangkan sehat dan makmur buah dari kebenaran atau hidup benar.

Damara dan Panjaitan menyatakan bahwa fenomena yang terjadi saat ini, penderitaan seringkali diidentikkan dengan perbuatan dosa. Setiap hal yang berkaitan dengan penderitaan, baik dalam segi ekonomi maupun kesehatan, sering dimakna sebagai suatu akibat dari dosa. Menurut Damara dan Panjaitan, pemikiran teologis ini mengakibatkan manusia mengalami pendangkalan pola pemikiran terhadap setiap peristiwa yang terjadi dalam kehidupan manusia. Paham ini menjadikan kinerja Tuhan menjadi dangkal dan terbatas seolah-olah Allah tidak dapat menghadirkan kekreatifan-Nya untuk berkarya melalui kuasa-Nya. Sejatinya Allah itu dinamis dan aktif dalam melakukan segala sesuatu sesuai dengan kehendak-Nya sendiri dan tidak dapat dibatasi oleh konsep atau teologi retribusi. ${ }^{22}$

Kitab Ayub memperlihatkan suatu hal yang kontraproduktif di tengah-tengah masyarakat. Mereka menjumpai kehidupan orang saleh justru menderita, sementara orang-orang fasik beroleh kehidupan yang lebih enak dan luput dari segala penderitaan. Paham teodisi inilah yang dipegang oleh masyarakat pada umumnya di zaman Ayub, dan juga dipegang oleh para sahabat Ayub tersebut. Paham teodisi ini telah mengakar kuat menjadi paham tradisional atau dikenal sebagai paham ortodoksi untuk menilai segala kejadian, sehingga hal itu menimbulkan kesalahpahaman tentang pribadi dan karya

12 Nathanael Yoel Damara; Firman Panjaitan, “Analisa Kritis Terhadap Konsep Allah Yang Tidak Kreatif Dalam Teologi Retribusi Kitab Ayub," Jurnal Teruna Bhakti 3, no. 2 (2021): 98-109. 
Allah bagi manusia. Ternyata paham ortodoksi ini tidak dapat memecahkan persoalan penderitaan Ayub. Narator kitab Ayub menegasikan bahwa penderitaan 'tidak mutlak' merupakan tanda keberdosaan.13 Dikatakan Maiaweng, memang iblis itu memiliki kuasa yang dapat mendatangkan bencana alam, sakit penyakit dan pelbagai penderitaan manusia, tetapi tetaplah Allah yang berdaulat atas iblis. Allah pun yang berdaulat atas Ayub, hambaNya yang setia. ${ }^{14}$ Sebagaimana dilaporkan narator kitab Ayub, Ayub merupakan pribadi yang berintegritas di hadapan manusia dan Tuhan. Ayub memiliki kepribadian yang baik. Selain itu, Ayub sendiri menyatakan secara terbuka di depan teman-temannya bahwa dirinya adalah selalu menghindari untuk berbuat dosa di hadapan Tuhan. Tidak benar bahwa Ayub telah menyembunyikan dosa sebagaimana yang dituduh kepadanya.

\section{Kesehatan Tubuh adalah Tanggung Jawab Manusia}

Allah menghendaki manusia memiliki tubuh yang sehat, sebab itu manusia diperintahkan untuk menjaga dan merawatnya. Pemeliharaan kesehatan tubuh merupakan tanggung jawab manusia. Kesehatan itu tidak bertahan dengan sendirinya, melainkan diperoleh lewat pemeliharaan. Orang Kristen bertanggung jawab untuk memelihara kesehatan tubuhnya yang adalah bait Allah (1 Kor 6:19-20; Rm 13:14).

Tuhan telah merancang kerja manusia selama 6 hari dan pada hari ketujuh harus beristirahat dari semua pekerjaan (Kej 2:1-3). Pola tertib ini berlaku hingga hari ini (Ul 5:13). Hal itu dimaksudkan agar manusia bisa mengatur kesehatan tubuhnya (penggunaan tenaga) secara baik, tepat dan bertanggung jawab demi kepentingan manusia sendiri dan juga untuk

\footnotetext{
${ }^{13}$ Kalis Stevanus, "Kesadaran Akan Allah Melalui Penderitaan Berdasarkan Ayub 1-2," Dunamis: Jurnal Teologi Dan Pendidikan Kristiani 3, no. 2 (2019): 11934, https://doi.org/10.30648/dun.v3i2.182.

14 Peniel C.D. Maiaweng Irvin Tolanda, "Kedaulatan Allah Atas Iblis Berdasarkan Kitab Ayub Pasal 1 Dan 2
}

memuliakan nama-Nya seperti dinasihatkan supaya orang Kristen mempersembahkan tubuhnya sebagai persembahan yang hidup, yang kudus dan yang berkenan kepada Allah (Rm.12:1). Ada banyak ayat-ayat berhubungan erat soal hukum-hukum mengenai makanan yang boleh dimakan dan yang dilarang di makan (Im 11:1-47; Ul 14:3-21).

Soal larangan tentang makanan dalam hukum Taurat, Sabdono menjelaskan alasan Allah mengatur jenis makanan apa yang dilarang untuk dikonsumsi manusia, Ia memberi stempel 'haram' bagi umat Israel. Peraturan mengenai haram dan halal untuk makanan di Israel dimaksudkan agar umat-Nya itu memiliki tubuh yang sehat. Sebab apa yang dikonsumsi pasti memiliki dampak atas fisik atau tubuh seseorang. ${ }^{15}$ Di dalam Injil pun, Kristus mengajarkan pentingnya supaya murid-muridNya bertanggung jawab atas kesehatan tubuhn mereka sendiri. Kristus menasihati para murid untuk beristirahat setelah melakukan perjalanan pelayanan dan lelah bahkan tidak sempat makan (Mrk.6:30-32). Apa yang dilakukan-Nya itu menjadi peringatan sekaligus contoh pentingnya pemeliharaan kesehatan tubuh. Bahkan Kristus menyatakan bahwa memiliki tubuh yang sehat merupakan ekspresi kasih kepada Bapa (Mrk.12:30).

Uraian di atas tampak jelas, disimpulkan bahwa Kristus bukan hanya memerhatikan soal spiritual atau aspek rohaniah saja, namun juga soal badaniah (kesehatan tubuh). Itulah sebabnya Paulus meminta kepada Timotius agar menjaga kesehatan tubuhnya yang sering lemah demi tugas pemberitaan Injil (1 Tim 5:23). Sebenarnya Tuhan hendak mengajarkan kepada umat-Nya tentang perlunya selektif memilih makanan yang dikonsumsi: mana yang menyehatkan tubuh dan yang dapat merusak

Serta Relevansinya Dalam Kehidupan Orang Percaya," Jaffray Vol.9, no. No.2 (2011): 53-89.

15 Erastus Sabdono, TRUTH, 111th ed. (Jakarta: Rehobot Literature, 2014),22. 
kesehatan tubuhnya. Penting sekali memerhatikan aspek kesehatan tubuh. Pola makan yang salah apa yang dikonsumsi manusia berdanpak negatif dan merugikan manusia sendiri. Kekristen mengajarkan betapa penting dan perlu pengelolaan kesehatan tubuh. Setiap orang Kristen bertanggung jawab untuk memelihara tubuhnya, sebab kita dipanggil untuk bertanggung jawab menjaga kesehatan tubuh dengan baik karena tubuh kita adalah bait Allah, milik Allah dan juga untuk melayani Allah (1 Kor 6:19-20).

\section{Sarana Kesembuhan Tubuh}

Allah memiliki banyak cara untuk menyediakan kuasa kesembuhan-Nya bagi umat manusia, antara lain sebagai berikut:

\section{Melalui kesembuhan natural (alamiah)}

Tuhan telah memperlengkapi di dalam tubuh manusia dengan sistem kesembuhan natural. Tuhan telah menciptakan tubuh manusia dengan kekuatan dan daya tahan untuk memulihkan diri sendiri. Tuhan menyediakan cara untuk melindungi dan menyembuhkan kesehatan manusia, dan salah satu di antara cara yang dipilih-Nya adalah sistem kekebalan tubuh. ${ }^{16}$ Rowlands menjelaskan di dalam tubuh manusia terdapat protein yang disebut fibrin di dalam darah. Contohnya, bila seseorang terluka dan mengalirkan darah keluar dari luka tersebut, maka fibrin tadi menyatu dan membentuk suatu lapisan kering. Hal itu akan menghentikan darah keluar. Selain itu, juga terdapat sela-sel darah putih sebagai bagian dari mekanisme pertahanan tubuh yang telah dibangun oleh Tuhan guna melindungi dan memulihkan sakit tubuh manusia. Jika ada suatu bakteri masuk dalam tubuh manusia, maka sel-sel darah putih segera melakukan perlawanan dan membunuhnya. ${ }^{17}$

Sebab itu, orang Kristen dipanggil untuk memelihara kondisi tubuh tetap sehat sehingga sistem kekebalan tersebut terus bekerja dengan baik. Abai terhadap pengelolan kesehatan tubuh dapat dikatakan telah merusak jalur kuasa kesembuhan-Nya bagi dirinya sendiri.

\section{Melalui kesembuhan medis (obat-obatan)}

Ada pandangan yang sangat ekstrim menentang orang pergi mengonsumsi obat karena dianggap kurang beriman karena tidak mempercayai kuasa Tuhan serta dianggap sikap melecehkan terhadap kuasa bilur-bilur Yesus. Pandangan demikian merupakan sikap yang keliru. Sebab dokter atau tenaga medis pun bisa menjadi sarana Tuhan untuk menyembuhkan kita. Sikap yang ekstrim dengan melarang orang berobat dapat berdampak buruk bagi dirinya sendiri. Orang Kristen tetap harus teguh berpegang bahwa kesembuhan pun tetap berasal dari Allah, tidak terbatas caranya entah melaui medis, mekanisme kekebabalan tubuh di dalam dirinya maupun kuasa mujizat-Nya.

Para dokter atau obat-obatan pun dapat menjadi salah alternatif yang dipakai Tuhan untuk memenuhi tujuan-tujuan-Nya dalam memberi kesembuhan kepada seseorang. Pengetahuan medis bekerjasama dengan hukum-hukum Tuhan untuk membantu pasien sembuh. Namun demikian, tetaplah hanya Tuhan yang dapat menyembuhkan. Boleh dikatakan, bila semua sakit penyakit selalu disembuhkan melalui mujizat kesembuhan Ilahi, tentu rumah sakit akan tutup. Tidak perlu lagi ada tenaga medis. Tapi realitanya, Tuhan tidak menghendaki dan melakukan-Nya. Sebaliknya, Tuhan dapat memakai para medis Kristen menjadi salah satu alternatif jalan kesembuhan. Melalui pekerjaan para medis Kristen orang-orang yang belum mengenal Tuhan dapat merasakan berkat-berkat Kerajaan Allah melalui pewartaan Injil.

Bila ke dokter dianggap kurang beriman dan melecehkan terhadap kuasa bilur-bilur Yesus, bagaimana dengan rasul Paulus? Ternyata rasul

\footnotetext{
${ }^{16}$ Regina Cherry, Pengobatan Injil, 30
} 
Paulus sendiri tidak menentang praktik penyembuhan melalui jasa medis. Padahal kita tahu bahwa Paulus telah melakukan banyak mujizat penyembuhan (Kis 14:8-11), tapi kenyataannya dia tidak dapat menyembuhkan rekan sekerja Epafroditus (Fil 2:25-30), Trofimus (2 Tim 4:20) dan Timotius (1Tim 5:23) yang sedang mengalami sakit tubuh mereka. Mungkinkah Paulus tidak mendoakan mereka? Mustahil. Siapakah yang berani mengatakan kalau mereka kurang beriman? Apakah mereka kurang beriman? Mustahil. Mereka adalah orang-orang yang mengabdikan diri penuh menjadi pelayan-pelayan Injil yang perlu disangsikan lagi keimanan mereka. Mereka adalah orang-orang yang tangguh dalam pelayanan pekabaran Injil bersama Paulus. Mereka adalah penginjil-penginjil hebat pada abad lalu.

Larry Parker mengatakan untuk kasus seperti Timotius, Epafroditus dan Trofimus kemungkinan besar Paulus telah belajar tentang perawatan dan penyembuhan terhadap penyakit itu dari dokter Lukas yang selalu pergi bersamanya (2 Tim 4:1; Kol 4:14). Maka penerapan kita adalah bukan karena kurang percaya pada kedahsyatan kuasa Tuhan, tapi karena Tuhan juga berkehendak memakai medis (obat-obatan) untuk menyalurkan kuasa kesembuhan-Nya kepada seseorang. Sebab itu, Parker menyarankan agar kita jangan menahan atau menolak tenaga medis dan obat-obatan bagi mereka yang benar-benar memerlukannya. ${ }^{18}$ Nyata di Alkitab tidak ada larangan menggunakan obat atau menggunakan jasa medis dalam merawat orang sakit atau memberantas suatu penyakit. Dengan kata lain, orang Kristen sah menggunakan jasa medis dan obat-obatan guna memeroleh kesembuhan dan kesehatan tubuhnya demi memuliakan nama Tuhan.

\section{Melalui kesembuhan Ilahi (Mujizat Kesembuhan)}

\section{Pengertian dan Tujuan Mujizat}

Sebelum membahas lebih dalam soal mujizat kesembuhan, penulis memandang perlu terlebih dahulu menjelaskan pengertian atau istilah mujizat. Sangat setuju dengan apa yang dikatakan Alex Lim. Menurutnya, definisi akata atau istilah mujizat dalam Alkitab harus tepat karena kesalahan di dalam memformulasikannya dapat berakibat pada pemahaman yang salah pula. Secara etimologis, Lim menjelaskan mujizat di Alkitab ada beberapa istilah dipakai untuk menunjukkkan karya perbuatan Tuhan yang ajaib (Kel.15:11; Mat.11:20; Luk.19:37; Kis.10:38). Kadangkadang, kata "mujizat" ini diartikan pertama adalah "keajaiban" (Kel.15:11; Kis.4:30; Rm.15:19). Kedua diartikan sebagai "kuasa, kekuatan dan kesanggupan" dalam bahasa Yunaninya "dunamis" yang mana di dalam Perjanjian Baru khususnya yang dikerjakan oleh Tuhan Yesus (Mat.11:20; Luk.19:37), para rasul (Luk.9:1; Kis.19:11; 2 Kor.12:12), dan bahkan oleh orang-orang yang dirasuki roh jahat (Mat.7:22; Kis.8:10; Why.13:2-4). Arti ketiga adalah "semeion", contohnya yang diperbuatan Kristus (Yoh.2:11), oleh Allah (Yoh.3:2), dan kadang-kadang juga oleh kuasa kegelapan (2 Tes.2:9; Why.16:14; 19:20). Dengan demikian, dapat disimpulkan bahwa mujizat adalah suatu perbuatan supranatural, di luar logika dan kemampuan manusia. Semua mujizat yang berasal atau dikerjakan oleh Allah dalam Kristus pada akhirnya mencapai tujuannya, yakni mendatangkan kebaikan bagi semua manusia dan membawa kemuliaan bagi Allah saja (Mrk.9:30-31). ${ }^{19}$

Sabdono menyatakan mujizat-mujizat Yesus di dalam Injil bertujuan menarik atau mengarahkan orang-orang, agar mengenal diriNya sebagai Anak Allah, Mesias dan Tuhan. Dan
${ }^{18}$ Gerald Rowlands, Tongkat Gembala (USA: World Map, 2013), 711
19 Alex Lim, "Kuasa Setan Di Balik Kesembuhan Ilahi?: Suatu Telaah Terhadap Mukjizat Kesembuhan Ilahi Yang Kontroversial," veritas Vol.9, no. 2 (2008): 191-213. 
pada finalnya mereka dapat diselamatkan. Tidak ada tujuan mujizat yang lain, selain itu. ${ }^{20}$ Sebab itu, dapat ditarik suatu kesimpulan bahwa cerita-cerita mujizat (miracle-stories) yang dicatat di Alkitab dimaksudkan untuk menyatakan siapa Yesus sesungguhnya: Ia adalah Mesias, Juruselamat dan Tuhan yang penuh kuasa. Jadi, fokus mujizat-Nya adalah bersifat kristologis-soteriologis. Bukan sekadar menyelesaikan masalah manusia bertalian dengan kebutuhan fisik saja, tapi terutama adalah soal keselamatan jiwanya.

\section{Kisah Mujizat dalam Alkitab}

Kisah atau fenomena tentang kesembuhan tubuh (miracle stories) dicatat di PL dan PB menurut Mamahit baik mereka yang menerima maupun menolak tentang fenomena kesembuhan ilahi, sebenarnya mereka kesamaan prasuposisi. Sama-sama percaya bahwa fenomena mujizat itu adalah sah dan sangat alkitabiah. Sebab Alkitab sangat banyak mencatat peristiwa kesembuhan ilahi (mujizat). Tuhan memakai pelayanan para nabi untuk menyatakan kuasa-Nya melalui kesembuhan ilahi atau mujizat atas mereka yang mengalami sakit-penyakit. Misalnya Musa (Bil.12), Elia (1 Raj.17:17-24), Elisa (2 Raj.4:1-38; 5:1-17), Yesaya (Yes.38). Seperti di PB yang dikerjakan Tuhan Yesus Kristus (Mat.4:23; 8:14-17; Mrk.1:40-45; Luk.4:38-40; Yoh.5:5-9), dan oleh rasul-rasul-Nya (Kis.3:110; 5:12-16; 14:9-10; 19:1-22; 28:1-10). ${ }^{21}$

Catatan Alkitab tentang kejadian penyembuhan secara adikodrati atau mujizat, tidak dapat dibantah memang faktual. Karena itu, kejadian mujizat kesembuhan ilahi adalah benar-benar alkitabiah. Baik PL maupun PB, dicatat secara jelas dan konsisten oleh para penulis bahwa Allah adalah pribadi yang berkuasa untuk melakukan mujizat

\footnotetext{
${ }^{20}$ Erastus Sabdono, Satu-Satunya (Jakarta: Rehobot Literature, 2021),35.

${ }^{21}$ Ferry Y.Mamahit, "Menjawab Persoalan Teologis Tentang Konsep Dan Praktik Kesembuhan Ilahi," VERITAS Vol.13, no. no.2 (2012): 143-157.
}

kesembuhan ilahi terhadap segala penyakit atau kelemahan tubuh manusia. Santoso menyatakan perlu diakui fakta mengenai mujizat kesembuhan ilahi di PB sentralnya adalah Tuhan Yesus. Belum lagi mujizatmujizat kesembuhan yang dilakukan oleh para rasul yang dicatat di Kisah Para Rasul. Menurut Santosono, hal ini membuktikan adanya regenerasi pelayanan kuasa mujizat kesembuhan dan bahwa nama Tuhan Yesus tetap masih berkuasa. ${ }^{22}$

Apalagi di PB, terutama di Injil-injil sangat limpah catatan kisah yang dialami oleh banyak orang tentang kesembuhan tubuh melalui pelayanan Yesus yang menyembuhkan sakit kusta (Mat.8:1-4); demam (Mat.8:14-17); lumpuh (Mat. 9:1-8; Mrk.2:1-12; Luk.5:17-26; Yoh.51-18); pendarahan (Mat.9:18-26; Mrk.5:21-43; Luk.8:40-56), orang buta (Yoh.9:1-41); dan masih banyak kisah penyembuhan tubuh lainnya dicatat di dalam Injil-injil. Ia pun memberi perintah kepada keduabelas rasul-Nya untuk pergi menyembuhkan orang-orang sakit (Mat 10:1,7,8; Luk 9:1-2), mengusir setan, mendemonstrasikan Kerajaan Allah dengan kuasa (Mrk 16:15-20).

Dari ayat-ayat yang dipaparkan di atas, mujizat bagi kesembuhan tubuh adalah alkitabiah dan tentu saja harus diterima sepenuhnya oleh umat Kristen. Mujizat tersebut masih berlaku atau dapat terjadi hingga abad modern ini, kendati pun tidak banyak. Hal ini dibuktikan sebagaimana dikatakan Paulus bahwa mujizat karunia kesembuhan ilahi masih berlangsung kesudahan alam, Yesus datang kembali (1 Kor.1:7;13).

\section{Iman, kedaulatan Tuhan, dan Mujizat}

Salah satu penyataan kekuatan kuasa Allah 
adalah terhadap sakit penyakit manusia. Sepanjang Alkitab menunjukkan Allah dipahami sebagai Tuhan Penyembuh (Kel.15:26； 23:25； Mzm.103:3-4； 107:20; Yer.30:17; Mat.9:12; 1 Ptr.2:24). Di mana kesembuhan ilahi 'selalu' terjadi oleh karena karya Tuhan sendiri dalam kedaulatan-Nya dan untuk menyatakan kekuasaan-Nya. Karena itu, jelas bahwa mujizat kesembuhan adalah karya Allah yang sifatnya anugerah semata. Namun, Dia juga dapat menyembuhkan secara spontan-suprantural atau kuasa mujizat-Nya melalui seseorang yang dikaruniai karunia mujizat kesembuhan ilahi. Hal itu tetap tergantung pada kehendak-Nya dan kedaulatan-Nya. Bila Tuhan berkehendak untuk menyembuhkan seseorang, pasti terjadi pernyataan mujizat-Nya. Sebaliknya, bila tidak, maka tidak terjadi mujizat (sekali pun didoakan oleh seseorang yang memiliki karunia kesembuhan). ${ }^{23}$

David Smith di dalam bukunya Bagaimana Aku dapat Meminta untuk Kesembuhan fisik?: Panduan Alkitabiah, yang dikutip Ronda, Smith menguraikan secara alkitabiah bertalian dengan kesembuhan fisik bahwa itu adalah kedaulatan atau prerogratif Allah tanpa harus mempertanyakan iman orang yang sakit itu. Tuhan berhak menyembuhkan manusia dengan cara yang dipilih-Nya, entah melewati proses medis, atau bahkan melalui kematian untuk menyempurnakannya dan masuk sorga. 24

Orang Kristen seharusnya berpikir positif sebagaimana dimaksud Alkitab sebagai sikap ketertundukan dengan menerima segala kejadian hidupnya dengan bercermin pada kedaulatan Tuhan yang sempurna. Bukan sebaliknya berubah prinsipnya menjadi possiblity thinking yang berdasarkan "kemauan sendiri", di mana iman sekadar alat

\footnotetext{
${ }^{23}$ Stevanus, Penyesatan Terselubung Dalam Gereja Masa Kini.

24 David J. Smith, "Bagaimana Aku Dapat Meminta Allah Untuk Kesembuhan Fisik?: Panduan Alkitabiah," JURNAL JAFFRAY Vol.13, no. 1 (2015): 140.
}

motivasi diri untuk mengharuskan Allah menjawab doa orang beriman. Klaim sugesti inilah yang dimaksudkan dengan "perkataan iman" yang pasti. Pendapat yang mengatakan asal mengimani dengan kuat maka Tuhan mau bertindak menyembuhkan. Seakan-akan kesembuhan bukanlah karya Tuhan, tetapi dari usaha manusia. Padahal jelas, semua bergantung pada kedaulatan-Nya sebab kesembuhan adalah anugerah semata. Siburian menyatakan keprihatinannya terhadap konsep yang keliru tentang mujizat kesembuhan ilahi. Sangat disayangkan, para "penyembuh" tersebut "kurang" menekankan Pribadi Yesus (Christ-centered) yang adalah sumber dari kuasa tersebut. Kelompok Kristen tertentu menganggap yang terpenting adalah kuasa dibalik nama yang dipakai sebagai formula penyembuhan. Mereka hanya menggunakan nama Yesus sebagai alat kuasa ajaib. ${ }^{25}$

Memang tidak dapat disangkal bahwa ada hubungan erat antara iman dan kesembuhan. Namun kenyataan meskipun sudah beriman, "iman yang kuat" baik yang mendoakan dan yang didoakan tidak terjadi kesembuhan. Seperti pengalaman Paulus sendiri, yang telah bergumul dalam doanya sebanyak tiga kali untuk kesembuhan tubuhnya yang sakit. Namun kenyataannya dia sendiri harus menghadapi realita tetap mengidap penyakit yang disebutnya "duri dalam daging" hingga akhir hayatnya (2 Kor 12: 7-9). Mungkinkah Paulus tidak beriman atau lemah iman? Hanya Tuhan yang tahu. Janganlah kita berspekulatif dalam perkara ini. Paulus telah dipakai Tuhan begitu luas dengan disertai tanda-tanda mujizat dan kesembuhan ilahi.

Rimun menyatakan rasul Paulus sejak pertobatannya berjumpa dengan Tuhan Yesus, ia sangat gigih dalam melakukan perintah Allah yang ditunjukkan dengan sangat jelas, tegas dan 
berani menyerahkan hidupnya sebagai seorang rasul hingga akhirnya mati martir. ${ }^{26}$ Paulus tidak patah semangat dan kendor dalam pelayanan pekabaran Injil sekalipun tetap mengidap penyakit atau penyakitnya tidak disembuhkan oleh Tuhan. Di dalam suratnya 2 Korintus 4:16-18 dan 2 Korintus 12:7-9 Paulus justru bersyukur atas keberadaannya tersebut dan tetap bersemangat dalam pekerjaan pekabaran Injil. Pengalaman Paulus tersebut memberi pelajaran bagi orang Kristen adalah pertama bahwa Tuhan "tidak selalu" menyembuhkan sakit tubuh kita dengan mujizat kesembuhan ilahi, sebaliknya Dia memberikan keteguhan iman sebagaimana dialami oleh Paulus. Imannya makin teguh dalam Tuhan walaupun tubuhnya sakit. Kedua, semua perbuatan ajaib Tuhan tidak pernah berpusat pada manusia, karena kuatnya manusia mengimani, tapi sebaliknya pada pribadi Tuhan (God-centered). Jadi, fokusnya bukan pada "kekuatan iman" dari orang seseorang (yang mendoakan maupun yang didoakan), melainkan pada pribadi Tuhan Yesus sebagai Penyembuh yang berkuasa untuk menyembuhkan (1 Kor.12:6).

Di tengah suasana berkembanganya berbagai penyakit, pola hidup dan pola makan yang cenderung sembrono, polusi udara yang buruk, kesibukan hidup, kurangnya latihan badani, biaya pengobatan tinggi ditambah krisis ekonomi, maka kebaktian kebaktian rohani dengan propaganda ada kesembuhan Ilahi banyak digandrungi orang Kristen. Dijanjikan oleh pengkhotbah yang mengaku memiliki karunia kesembuhan ini, bahwa kuasa Yesus tetap sama, dahulu, kemarin, hari ini dan sampai selama-lamanya (Ibr.13:8). Dia pasti akan menyembuhkan umat-Nya yang memercayai bilur-bilur-Nya. Hemat penulis, justru ini adalah cara-cara yang tidak alkitabiah menyelesaikan persoalan kesehatan fisik dengan tidak dewasa dan menjadikan manusia malas dan abai dengan 'mengkampanyekan kuasa bilur-bilur Tuhan Yesus'. Pemberitaan yang salah mengenai kuasa bilur Yesus guna kesembuhan tubuh dapat mengakibatkan penyimpangan teologis, yang ujungnya berakhir pada "penyesatan". Karena itu, penting memahami kebenaran mengenai penyakit dan kesembuhannya.

\section{Implikasi}

\section{Implikasi Teologis}

Orang Kristen harus tetap yakin dan dapat memercayai bahwa Tuhan masih berkuasa melakukan tanda-tanda ajaib seperti menyembuhkan berbagai penyakit secara ajaib hingga hari ini. Orang Kristen boleh mengharapkan akan mujizat kesembuhan ilahi itu untuk dapat dialami dalam hidupnya, tetapi tidak boleh memaksakan kesembuhan sekehendak imannya, seolah-olah mujizat terjadi disebabkan pada kuatnya keyakinan (iman) seseorang. Perbuatan ajaib Allah hanya bergantung karya Allah dalam kedaulatan-Nya yang sempurna. Sebaiknya orang Kristen harus menerima dan yakin bahwa Tuhan dapat melakukan mujizat-Nya untuk menyembuhkan dengan cara yang dipilih-Nya entah melalui proses alamiah, mujizat maupun medis.

Lebih dari itu, orang Kristen perlu waspada terhadap berbagai fenomena ajaib. Semuanya itu perlu diuji dengan ujian yang obyektif, yaitu Alkitab sebab bukan tidak mungkin kejaiban itu dikerjakan oleh kuasa kegelapan. Alkitab telah memberi peringatan adanya praktik pemalsuan dari kuasa kegelapan melalui orang-orang tertentu (Mat.24:24).

\section{Implikasi Praktis}

Sekalipun karunia mujizat kesembuhan ilahi masih berlangsung hingga hari ini, orang Kristen tidak boleh abai melepaskan tanggung 
jawab untuk merawat kesehatan tubuhnya. Tidak boleh sembrono mengelola tubuh karena ada penyediaan mujizat kesembuhan. Penting orang Kristen menjalani hidup ini dengan tetap memperhatikan keseimbangan sistem kerja organ dalam tubuhnya. Menjaga kesehatan tubuh merupakan kehendak Tuhan tapi manusialah yang harus mengusahakannya dengan baik agar terhindar dari segala sakit penyakit yang dapat menghambat segala aktivitas dan tidak produktif. Jadi, Tuhan bekerja, orang Kristen pun turut bekerja melakukan bagiannya dengan memerhatikan aspek kesehatan tubuhnya adalah bait Roh Kudus yang harus dipertanggung jawabkan kepada-Nya.

\section{Kesimpulan}

Menyoal tentang kesembuhan tubuh, perlu dimengerti bahwa kesembuhan tubuh dapat terjadi melalui beberapa jalan yang dipilihNya, yaitu terjadi secara alamiah, melalui bantuan medis (obat-obatan), dan tentu saja dengan kuasa supernatural yang disebut dengan mujizat kesembuhan.

Dari pengertian ini, diperoleh implikasi secara teologis, bahwa karunia mujizat untuk kesembuhan ilahi masih dapat berlaku dan terjadi sekarang. Namun, orang Kristen tetap harus berhati-hati dan bersikap kritis terhadap berbagai fenomena ajaib supaya tidak terjebak pada pemalsuan kuasa gelap melalui orangorang tertentu. Dan secara praktis, orang Kristen harus bertanggungjawab aktif menjaga dan merawat kesehatan tubuhnya yang adalah bait Allah sehingga mengalami kebahagian dan produktif.

\section{Referensi}

Erastus Sabdono. TRUTH. 111th ed. Jakarta: Rehobot Literature, 2014.

Irvin Tolanda, Peniel C.D. Maiaweng. "Kedaulatan Allah Atas Iblis Berdasarkan Kitab Ayub Pasal 1 Dan 2 Serta Relevansinya Dalam Kehidupan Orang Percaya.” Jaffray Vol.9, no. No.2
(2011): 53-89.

Lim, Alex. "Kuasa Setan Di Balik Kesembuhan Ilahi?: Suatu Telaah Terhadap Mukjizat Kesembuhan Ilahi Yang Kontroversial." veritas Vol.9, no. 2 (2008): 191-213.

Marbun, Kalis Stevanus; Stefanus. "Memaknai Kisah Ayub Sebagai Refleksi Iman Dalam Menghadapi Penderitaan." LOGIA: Jurnal Teologi Pentakosta 1, no. 1 (2019): 23-40.

Panjaitan, Nathanael Yoel Damara; Firman. "Analisa Kritis Terhadap Konsep Allah Yang Tidak Kreatif Dalam Teologi Retribusi Kitab Ayub.” Jurnal Teruna Bhakti 3, no. 2 (2021): 98-109.

Pranoto, Minggus Minarto. "Kesembuhan, Penebusan, Dan Kebaikan Allah Dalam Teologi Pentakostal.” Jurnal Abdiel: Khazanah Pemikiran Teologi, Pendidikan Agama Kristen dan Musik Gereja 1, no. 1 (2017): 81-98.

Regina Cherry. Pengobatan Injil. Batam: Gospel Press, 2003.

Rimun, Robinson. "Latar Belakang Hidup Dan Pendidikan Rabinik Paulus Dalam Kaitannya Dengan Perjumpaannya Dengan Kristus.” PASCA : Jurnal Teologi dan Pendidikan Agama Kristen (2019).

Rowlands, Gerald. Tongkat Gembala. USA: World Map, 2013.

Sabdono, Erastus. Satu-Satunya. Jakarta: Rehobot Literature, 2021.

Santoso, Budiman. "Teologi Mujizat Kesembuhan." Jurnal Pembaharu 5, no. 2 (2019).

Siburian, Togardo. "Tinjauan Ulang Terhadap 'Kesembuhan Ilahi”.” STULOS Vol.17, no. no.1 (2019): 28-53.

Silalahi, Djaka Christianto. Karismatik Bercampur Dengan Perdukunan? Yogjakarta: Andi Offset, 2001.

Smith, David J. "Bagaimana Aku Dapat Meminta Allah Untuk Kesembuhan Fisik?: Panduan Alkitabiah.” JURNAL JAFFRAY Vol.13, no. 1 (2015): 140.

Stevanus, Kalis. Ada Penyesat Yang Memplesetkan Injil Dalam Jemaat, Apa Sikap Anda. Yogjakarta: Pustaka Nusatama, 2016.

--_. "Kesadaran Akan Allah Melalui Penderitaan Berdasarkan Ayub 1-2." DUNAMIS: Jurnal Teologi dan Pendidikan Kristiani 3, no. 2 (2019): 111. 
Penyesatan Terselubung Dalam Gereja Masa Kini. Yogyakarta: Randa's Family, 2007.

. Penyesatan Terselubung Dalam Gereja Masa Kini. Yogjakarta: Randa's Family, 2017.

Sukono, Djoko. “Alkitab: Penyataan Allah Yang Diilhamkan.” PASCA: Jurnal Teologi dan Pendidikan Agama Kristen 15, no. 1 (November 30, 2019): 28-34. https://journal.stbi.ac.id/index.php/PSC/arti cle/view/66.

Y.Mamahit, Ferry. "Menjawab Persoalan Teologis Tentang Konsep Dan Praktik Kesembuhan Ilahi." VERITAS Vol.13, no. no.2 (2012): 143157.

Zaluchu, Sonny E. "The Impact of Mediatisation in the Healing Ministry of African Preachers." Verbum et Ecclesia 42, no. 1 (April 20, 2021). http://www.ve.org.za/index.php/VE/article/v iew/2198.

Zaluchu, Sonny Eli. "Strategi Penelitian Kualitatif Dan Kuantitatif Di Dalam Penelitian Agama." Evangelikal: Jurnal Teologi Injili dan Pembinaan Warga Jemaat 4, no. 1 (January 31, 2020): 28-38.

https://journal.sttsimpson.ac.id/index.php/E JTI/article/view/167. 